\title{
Coffee reduces KRAS expression in Caco-2 human colon carcinoma cells via regulation of miRNAs
}

\author{
TAKUYA NAKAYAMA, MEGUMI FUNAKOSHI-TAGO and HIROOMI TAMURA \\ Graduate School of Pharmaceutical Sciences, Keio University, Tokyo 105-8512, Japan
}

Received December 12, 2015; Accepted February 17, 2017

DOI: $10.3892 / 01.2017 .6227$

\begin{abstract}
Previous epidemiological studies have demonstrated that moderate coffee consumption is associated with a lower risk of certain types of cancer, particularly colon cancer. To elucidate the molecular basis for this protective action, the effect of coffee on Caco-2 human colon carcinoma cells was investigated. Low concentrations of coffee $(<5 \%)$ inhibited proliferation of Caco- 2 cells without affecting cell viability. Coffee also reduced KRAS proto-oncogene, GTPase (KRAS) gene expression in a dose-dependent manner; however, caffeine, caffeic acid and chlorogenic acid, three major constituents of coffee, did not exhibit this effect. Increasing the duration of coffee bean roasting increased the reduction in KRAS expression, suggesting that the active constituents responsible for this effect emerged during the roasting process. MicroRNA (miR) analysis revealed that coffee induced the expression of miR-30c and miR-96, both of which target the KRAS gene. The results of the present study suggested that daily coffee consumption may reduce KRAS activity, thereby preventing the malignant growth of colon carcinoma cells.
\end{abstract}

\section{Introduction}

Coffee is widely consumed as a beverage globally, and a moderate intake of coffee has been linked to a reduced risk of chronic diseases, including type 2 diabetes (1), Parkinson's disease (2) and liver disease (3). Multiple epidemiological studies have demonstrated an inverse association between coffee consumption and risk of colorectal cancer (4-6). However, the molecular basis of this effect remains to be fully understood (7).

Colorectal cancer is one of the most common malignancies in the westernized world. An important step in the progression of colorectal cancer is the induction of activating mutations in KRAS proto-oncogene, GTPase (KRAS). Mutations in

Correspondence to: Professor Hiroomi Tamura, Graduate School of Pharmaceutical Sciences, Keio University, 1-5-30 Shibakoen, Minatoku, Tokyo 105-8512, Japan

E-mail: tamura-hr@pha.keio.ac.jp

Key words: Caco-2, coffee, colon cancer, KRAS, miRNA, roasting
$K R A S$ appear in the intermediate adenoma stage, early during tumorigenesis, and it is thus possible to use them as a biomarker for early detection of $\sim 40 \%$ of colorectal tumors (8).

Activated KRAS regulates multiple downstream pathways involved in cancer development, including the mitogen-activated protein kinase (MAPK) and phosphatidylinositol 3-kinase (PI3K) signaling pathways (9), via the action of epidermal growth factor (EGF). The EGF receptor is involved in regulating normal growth and contributes to the malignant growth of several tumor types, including colon cancer (10) by phosphorylating tyrosine residues in trans within the cytoplasmic domain of the receptor to activate Ras and other downstream effectors. Therefore, the present study investigated the effects of coffee on KRAS signaling via EGF in human colon cancer Caco- 2 cells.

\section{Materials and methods}

Materials. Caco-2 human colon carcinoma cells were obtained from the RIKEN BioResource Center (Tsukuba, Japan). Colombian Arabica coffee beans were purchased from Yanaka Coffee Co., Ltd. (Tokyo, Japan). Reagents for PCR were purchased from Applied Biosystems; Thermo Fisher Scientific, Inc. (Waltham, MA, USA). Reagents for quantification of microRNA (miRNA/miR) were purchased from Qiagen GmbH (Hilden, Germany). Antibodies for MAPK (cat. no., 9102), phosphorylated (p-) MAPK (cat. no., 9101), protein kinase B (Akt; cat. no., 9272) and p-Akt (cat. no., 9271) were purchased from Cell Signaling Technology, Inc. (Danvers, MA, USA). Antibodies for K-ras (cat. no., sc-30) and $\beta$-actin (cat. no., sc-58673) were purchased from Santa Cruz Biotechnology, Inc. (Dallas, TX, USA). Caffeine, caffeic acid, chlorogenic acid and trigonelline were purchased from Sigma-Aldrich; Merck KGaA (Darmstadt, Germany). Human EGF was purchased from PeproTech (Rocky Hill, NJ, USA).

Coffee preparation. Roasted and ground coffee (Colombian Arabica) was obtained from Starbucks Corporation (Seattle, WA, USA). Coffee extracts were prepared by a commonly utilized method, where $8 \mathrm{~g}$ of ground coffee was extracted with $140 \mathrm{ml}$ hot water $\left(95^{\circ} \mathrm{C}\right)$. The extract was then filtered through a paper filter (Mellita Group, Minden, Germany), divided into small aliquots and stored at $-80^{\circ} \mathrm{C}$ until used. Undiluted extract, with a dry weight of $8.4 \mathrm{mg} / \mathrm{ml}$, was assigned a concentration of $100 \%(\mathrm{v} / \mathrm{v})$. For roasting experiments, green Colombian 
Arabica coffee beans were purchased from Yanaka Coffee Co., Ltd. Green coffee beans were roasted at $200-220^{\circ} \mathrm{C}$ for up to $20 \mathrm{~min}$. Coffee extracts were prepared and stored as described for roasted and ground coffee. Optical densities at $500 \mathrm{~nm}$ of $10 \%$ brewed coffee made from roasted beans were 0.05 (green beans), 0.153 (medium roasted beans) and 0.269 (dark roasted beans), respectively.

Cell culture and coffee treatment. Caco-2 cells were grown in 6-well plates (Iwaki Co., Ltd., Tokyo, Japan) in $2 \mathrm{ml}$ Dulbecco's modified Eagle's medium (Nacalai Tesque, Inc., Kyoto, Japan) supplemented with $10 \%$ fetal bovine serum (Biological Industries USA, Cromwell, CT, USA), 2 mM glutamine, $10 \mathrm{U} / \mathrm{ml}$ penicillin, $10 \mathrm{U} / \mathrm{ml}$ streptomycin and additional non-essential amino acids (Sigma-Aldrich; Merck KGaA). Cells were seeded at a concentration of $1 \times 10^{5}$ cells $/ \mathrm{ml}$ and grown to $80-90 \%$ confluence (2-3 days) in an incubator at $37^{\circ} \mathrm{C}$ in a humidified atmosphere containing $5 \% \mathrm{CO}_{2}$. The medium was changed every 4-5 days. Cultured cells were exposed to coffee extracts at $0,0.31,0.63,1.25,2.5,3.75$ and $5.0 \%(\mathrm{v} / \mathrm{v})$ or caffeine, caffeic acid, chlorogenic acid, and trigonelline at $100 \mu \mathrm{M}$. Control cells were treated with $0.1 \%$ DMSO. Cell numbers and viability were analyzed using a Vi-Cell counter (Beckman Coulter, Inc., Brea, CA, USA) and a trypan blue exclusion assay using $0.4 \%$ trypan blue dye (Thermo Fisher Scientific KK, Yokohama, Japan).

Analyses of gene expression. Total RNA was isolated from the cultured cells using the Direct-zol ${ }^{\mathrm{TM}}$ RNA MiniPrep kit and TRIzol reagent (Zymo Research, Irvine, CA, USA). First-strand cDNA was synthesized from $1 \mu \mathrm{g}$ total RNA using 100 units $/ \mathrm{ml}$ of reverse transcriptase and random primers using a ReverTra-Plus Kit (TOYOBO, Osaka, Japan) according to the manufacturer's protocol. The primers used for the amplification of cDNAs were designed using a web application (Primer3) based on sequences obtained from the NCBI database. The sequences used were as follows: KRAS forward, 5'-CCTGCT GTGTCGAGAATATCCA-3' and reverse, 5'-TTGACGATA CAGCTAATTCAGAATCA-3'; 18S RNA forward, 5'-TGG TTGCAAAGCTGAAACTTAAAG-3' and reverse, 5'-AGT CAAATTAAGCCGCAGGC-3'. Quantitative polymerase chain reaction (qPCR) analysis was performed in a CFX96 Real Time PCR Detection System (Bio-Rad Laboratories, Inc., Hercules, CA, USA) using the SYBR Green PCR Core Reagent kit (Roche Diagnostics, Basel, Switzerland). Samples were denatured at $95^{\circ} \mathrm{C}$ for 10 min and amplified by 40 cycles of denaturation at $95^{\circ} \mathrm{C}$ for $15 \mathrm{sec}$, followed by annealing and extension at $60^{\circ} \mathrm{C}$ for $60 \mathrm{sec}$. The amount of target gene relative to the reference gene (18S rRNA) was quantified using the cycle threshold $(\mathrm{Cq})(11)$.

The cDNAs of miRNAs were synthesized from $250 \mathrm{ng}$ total RNA using the miScript II RT kit (Qiagen $\mathrm{GmbH}$ ) according to the manufacturer's protocol. Quantification of miRNAs was performed using the miScript SYBR Green PCR kit (Hs_miR-96_1 miScript Primer Assay and Hs_miR-30c_2 miScript Primer Assay; Qiagen $\mathrm{GmbH}$ ) using the aforementioned thermocycler conditions according to the manufacturer's protocol, and quantified using the cycle threshold $(\mathrm{Cq})(11)$. The Hs_RNU6-2_1 miScript Primer Assay (Qiagen GmbH) was used for normalization.
Western blotting. Cells were lysed in Nonidet P-40 lysis buffer (50 mM Tris- $\mathrm{HCl} \mathrm{pH} 8.0,120 \mathrm{mM} \mathrm{NaCl}, 1 \mathrm{mM} \mathrm{NaCl}, 1 \mathrm{mM}$ EDTA pH 8.0, 0.5\% Nonidet P-40), phosphatase inhibitor cocktail (Nacalai Tesque, Inc., Kyoto, Japan), and protease inhibitor cocktail (Nacalai Tesque, Inc.). Proteins $(20 \mu \mathrm{g})$ were resolved by $10 \%$ sodium dodecyl sulfate (SDS) polyacrylamide gel electrophoresis and then electrotransferred to a polyvinylidene difluoride membrane (Merck KGaA). The membrane was incubated for $1 \mathrm{~h}$ at room temperature in blocking buffer consisting of TBS $(20 \mathrm{mM}$ Tris- $\mathrm{HCl} \mathrm{pH}$ $7.4,137 \mathrm{mM} \mathrm{NaCl}$ ) containing 5\% skim milk. The membrane was incubated overnight at $4{ }^{\circ} \mathrm{C}$ with primary antibody. Primary antibodies were mouse monoclonal anti-K-ras (1:500), rat monoclonal anti-H-ras (1:500) and goat polyclonal anti- $\beta$-actin (1:2,000; Santa Cruz Biotechnology, Inc.); rabbit monoclonal anti-p44/42 MAPK [(extracellular signal related kinase $1 / 2($ ERK1/2; 1:1,000), rabbit monoclonal anti-p-p44/42 MAPK (ERK1/2; Thr202/Tyr204; 1:1,000), rabbit monoclonal anti-Akt (1:500) and anti p-Akt (1:1,000; Cell Signaling Technology, Danvers, MA, USA). The next day, the membrane was incubated with either anti-rabbit (cat. no., RPN4301), anti-mouse (cat. no., RPN4201) or anti-rat (cat. no., NA934) immunoglobulin G horseradish peroxidase-linked secondary antibodies (all 1:2,000; GE Healthcare Bio-Sciences, Pittsburgh, PA, USA) at room temperature for $60 \mathrm{~min}$. Immunoreactive proteins were visualized using an enhanced chemiluminescence western blotting detection system (GE Healthcare Bio-Sciences).

Analysis of effects of coffee on EGF signaling. Caco-2 cells were treated with $5 \%$ coffee for $24 \mathrm{~h}$, and then EGF $(50 \mathrm{ng} / \mathrm{ml})$ was added to the medium. Cells were harvested at $0,5,10$ and 15 min following the addition of EGF and the cell lysates (20 $\mu$ g protein) were analyzed by western blotting.

Statistical analysis. The Student's $t$-test was used for statistical analysis using a software (SPSS station, v. 23; IBM SPSS, Armonk, NY, USA), and $\mathrm{P}<0.05$ was considered to indicate a statistically significant difference.

\section{Results}

Coffee reduced proliferation of Caco-2 cells. Human colon carcinoma Caco-2 cells were treated with coffee extract (0-5\%) for up to 3 days. An inhibitory effect of coffee extract on cell proliferation was detected at concentrations of $1.25 \%$ and above, with complete inhibition observed at a concentration of $3.75 \%$ (Fig. 1A). No significant cytotoxicity was observed for coffee extract concentrations up to $3.75 \%$, even following incubation for 3 days (Fig. 1B).

Coffee reduced KRAS expression in Caco-2 cells. As the development and growth of colon cancer is associated with abnormal activation of the KRAS signaling pathway (12), KRAS expression in the coffee extract-treated Caco- 2 cells was measured. Coffee extract reduced the expression of the KRAS protein and KRAS mRNA in a dose-dependent manner (Fig. 2A and B, respectively). KRAS mRNA expression decreased to $<50 \%$ of the control level following treatment with $2.5 \%$ coffee extract for $24 \mathrm{~h}$. 
A

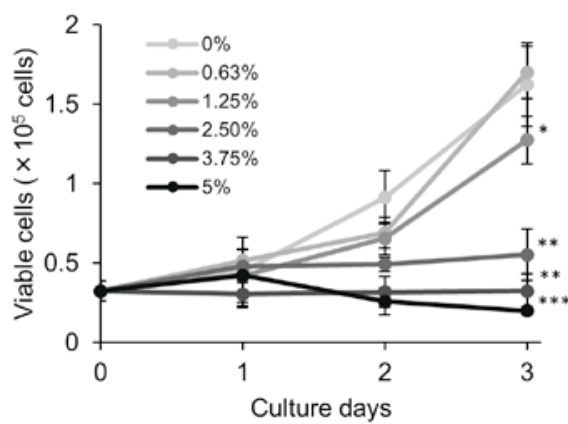

B

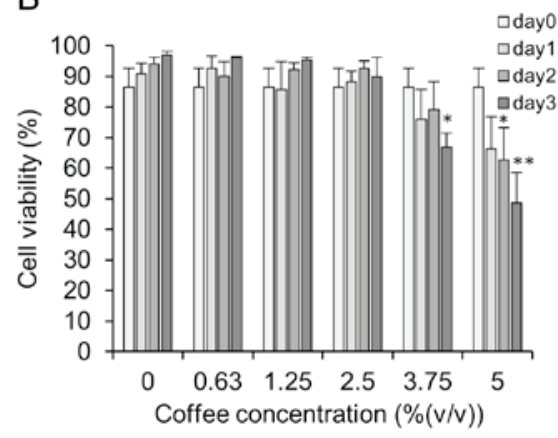

Figure 1. Coffee inhibits proliferation of Caco-2 cells. Caco-2 cells were treated with 0-5\% coffee extract for up to 3 days. On each day, cell number and viability were measured using a trypan blue exclusion assay. (A) Proliferation curve and (B) viability. ${ }^{*} \mathrm{P}<0.05,{ }^{* * *} \mathrm{P}<0.01$ and ${ }^{* * * *} \mathrm{P}<0.001 \mathrm{vs} .0 \%$ (n=3).

A

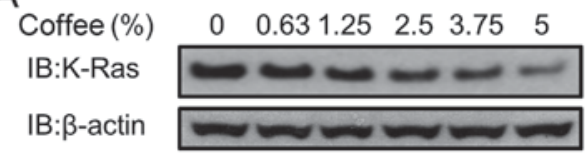

B

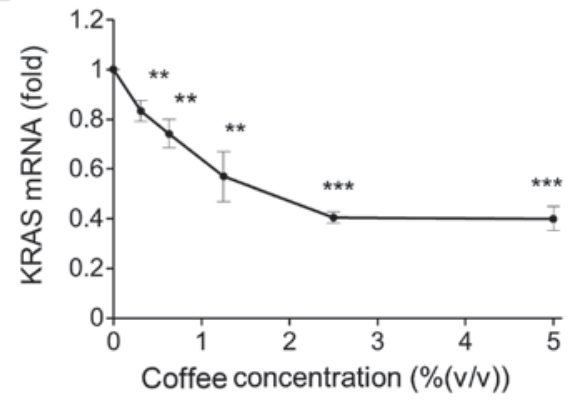

Figure 2. Coffee reduced KRAS expression in Caco-2 cells. Caco-2 cells were treated with $0-5 \%$ coffee for $24 \mathrm{~h}$, and KRAS expression was monitored by (A) western blot and (B) quantitative polymerase chain reaction. ${ }^{* *} \mathrm{P}<0.01$ and ${ }^{* * *} \mathrm{P}<0.001$ vs. $0 \%(\mathrm{n}=3)$. KRAS, KRAS proto-oncogene, GTPase.

In order to elucidate the effect of coffee on KRAS signaling pathways, the activation of Akt (PI3K pathway) and ERK (MAPK pathway) elicited by $50 \mathrm{ng} / \mathrm{ml}$ EGF in coffee extract-treated Caco-2 cells was analyzed. Phosphorylation of Akt and ERK was observed 5 min following addition of $50 \mathrm{ng} / \mathrm{ml} \mathrm{EGF}$ in cells untreated with coffee extract (Fig. 3). In contrast, phosphorylation of Akt and ERK occurred relatively slowly (at 15-30 min) in the coffee extract-treated cells (Fig. 3).

Characterization of active coffee constituents in coffee extracts. In order to elucidate which constituents were responsible for coffee extract-mediated reduction in KRAS expression, KRAS protein expression was measured following treatment of cells with $100 \mu \mathrm{M}$ caffeine, chlorogenic acid, caffeic acid or trigonelline. All these compounds are major constituents of coffee. None of these coffee constituents, except for trigonelline, altered KRAS expression (Fig. 4A), even though the concentration used was roughly equivalent to that present in in $10-50 \%$ coffee extracts (13). Weak reduction with trigonelline was detected.

In order to examine the possibility that constituents with KRAS expression-altering capabilities are formed during the roasting process, the activity of extracts of green coffee beans that had undergone varying degrees of roasting prior to brewing was assessed. Increasing the duration of roasting resulted in greater reduction in KRAS protein and mRNA expression (Fig. 4B and C, respectively).

Coffee induced miRNAs that target KRAS gene expression. Previous studies have revealed that several miRNAs are involved in the regulation of KRAS gene expression in colorectal cancers $(14,15)$. A preliminary microarray analysis of Caco-2 cell miRNAs following treatment with $2.5 \%$ coffee extract indicated that coffee induced expression of miR-30c and miR-96, which are known to target the KRAS gene (data not shown). Therefore, the expression of these miRNAs in coffee extract-treated Caco-2 cells was examined. The expression of miR-30c and miR-96 in Caco-2 cells was induced $3 \mathrm{~h}$ following the addition of 5\% coffee extract and gradually decreased to basal levels over time (Fig. 5A and B, respectively). Concomitantly, KRAS mRNA expression levels decreased $6 \mathrm{~h}$ following coffee extract treatment (Fig. 5C). The induction of miRNAs occurred in a dose-dependent manner (Fig. 5D).

\section{Discussion}

The present study reported that coffee extract reduced KRAS expression in Caco-2 human colon carcinoma cells. Coffee extract mediated these effects by activating two miRNAs, miR-30c and miR-96, which are known to target the KRAS gene (Fig. 5). Coffee inhibited the proliferation of Caco-2 cells. As KRAS is a key molecule for cell growth and proliferation mediated by EGF, the inhibition of cell proliferation following coffee extract may be due to the reduction of KRAS expression.

Previous studies have reported regulation of KRAS expression by miRNAs. For example, resveratrol prevents tumorigenesis of colorectal cancers by suppressing KRAS expression, which occurs by increasing miR-96 expression (14). Let-7a miRNA inhibits cell proliferation in the lung cancer cell line, 95D, by regulating the translation of KRAS mRNA (16). The miRNA miR-30c suppresses breast cancer cell growth, potentially through the inhibition of KRAS signaling (17). Similarly, in coffee extract-treated Caco-2 cells, elevated miR-30c and miR-96 may suppress KRAS expression, potentially by affecting KRAS mRNA stability (17). Further studies 


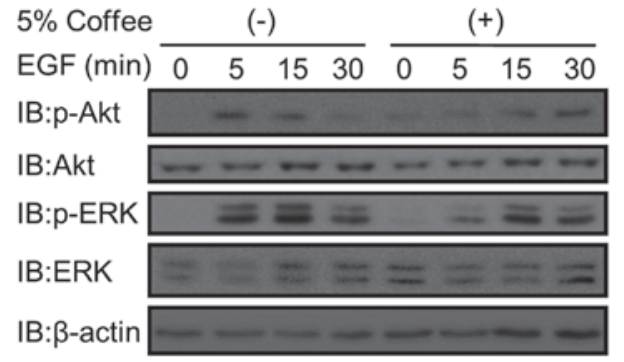

Figure 3. Coffee reduced EGF-induced activation of Akt and ERK in Caco-2 cells. Caco-2 cells were treated with $5 \%$ coffee for $24 \mathrm{~h}$, and then EGF $(50 \mathrm{ng} / \mathrm{ml})$ was added to the medium. Cells were harvested at the indicated times following the addition of EGF and the cell lysates (20 $\mu \mathrm{g}$ protein) were analyzed by western blotting. EGF, epidermal growth factor; Akt, protein kinase B; ERK, extracellular signal-related kinase; p-, phosphorylated.

are needed to clarify the mechanisms underlying regulation of miRNA expression by coffee extract.

The induction of miRNAs occurred $3 \mathrm{~h}$ following the addition of coffee extract and decreased following this. However, the reduction of KRAS expression started at $6 \mathrm{~h}$ and continued to $24 \mathrm{~h}$ (Fig. 5C). The initial reduction in KRAS expression by miRNAs may cause other cellular reactions to suppress the expression of KRAS gene. Further studies are necessary to clarify this issue.

Active constituents responsible for the reduction in KRAS expression in coffee extract-treated Caco- 2 cells were demonstrated to emerge during the roasting of coffee beans (Fig. 4B and C). A slight reduction in KRAS expression occurred following exposure to $100 \mu \mathrm{M}$ trigonelline, however, trigonelline is known to be decomposed by the roasting process. Therefore, trigonelline may not be responsible for the KRAS reduction observed following exposure to coffee extract. Multiple phenolic constituents and Maillard reaction products are known to form during the coffee bean roasting process (18-20). These compounds have been reported to possess various types of antioxidant and pro-oxidant activity $(21,22)$ and often modulate antioxidant transcription factors, including nuclear factor- $\kappa \mathrm{B}(\mathrm{NF}-\kappa \mathrm{B})$ and nuclear factor- $E_{2}$-related factor 2 . Furthermore, these compounds escape digestion and pass through the upper gastrointestinal tract into the colon (23). Thus, these compounds may be able to interact with colon epithelial cells.

Previous evidence has suggested that $\mathrm{NF}-\kappa \mathrm{B}$ is involved in the upregulation of $\mathrm{miR}-30 \mathrm{c}$ in several biological responses $(24,25)$. In addition, resveratrol, an antioxidant, activates miR-96 in sporadic colorectal cancer cells as mentioned above (14). Taken together with the results of the present study, coffee antioxidants that emerge during the roasting process may upregulate miR-30c in Caco-2 cells by activating NF- $\mathrm{B}$. Activated miR-30c may subsequently reduce KRAS expression in coffee extract-treated Caco- 2 cells. Coffee extract-induced $\mathrm{NF}-\kappa \mathrm{B}-$ mediated activation of the ATP binding cassette subfamily $\mathrm{G}$ member 2 (Junior blood group) gene has been observed in Caco-2 cells (26). Further studies are required to clarify the identities of the active constituents in order to validate this mechanism.

The results of the present study demonstrated that KRAS inhibition by coffee resulted in reduced proliferation of
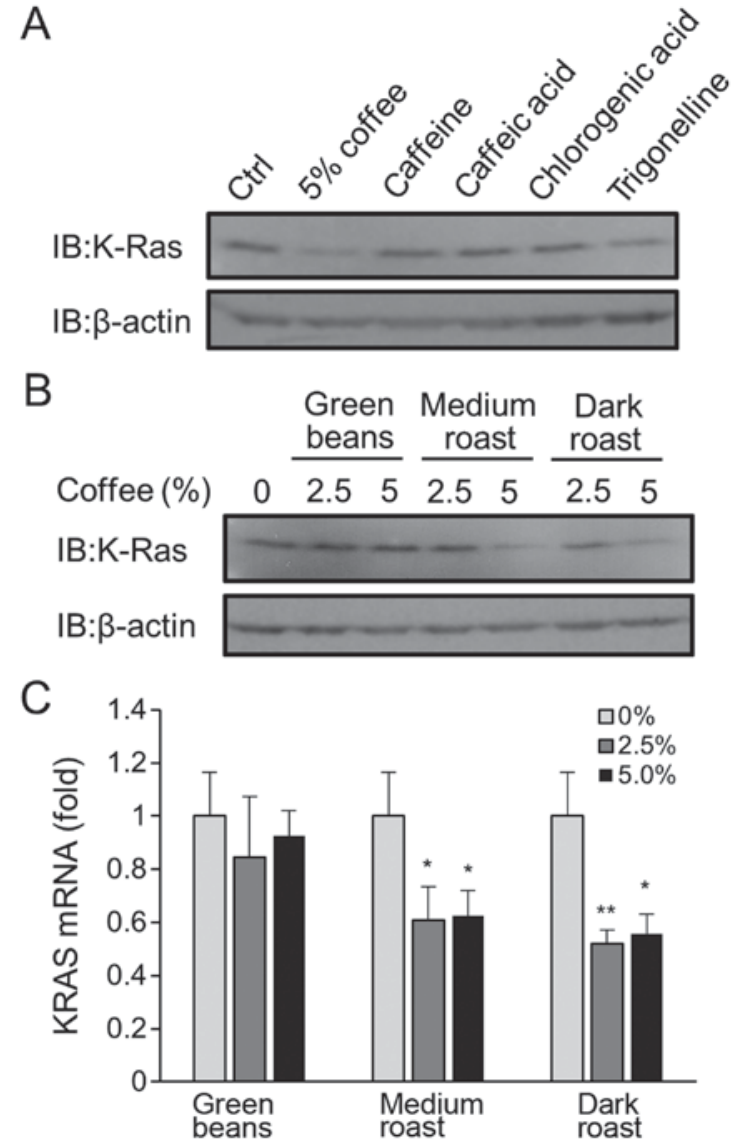

Figure 4. Effects of major coffee constituents and roasting levels on KRAS expression in Caco-2 cells. (A) Cells were treated with major coffee constituents (caffeine, caffeic acid, chlorogenic acid, and trigonelline) at $100 \mu \mathrm{M}$ for $24 \mathrm{~h}$, and the KRAS expression was monitored by western blotting. Cells were treated with coffee brewed from different roasts at concentrations of 2.5 and $5 \%$ for $24 \mathrm{~h}$, and KRAS protein and mRNA levels were analysed by (B) western blotting and (C) quantitative polymerase chain reaction. ${ }^{*} \mathrm{P}<0.05$ and ${ }^{* *} \mathrm{P}<0.01$ vs. $0 \%$. KRAS, KRAS proto-oncogene, GTPase; IB, western blotting; Cntl, $0.1 \%$ DMSO control.

Caco-2 human colon carcinoma cells through the regulation of miRNAs. Previous epidemiological studies indicated that coffee consumption is associated with a protective effect for colorectal cancer with a relative risk of 0.83 (95\% confidence interval: $0.75-0.92)$ in a previous meta-analysis $(27,28)$. The inhibitory effect of coffee extract on KRAS expression may be a key factor underlying the protective effects of coffee against colorectal cancer.

Mutational activation of KRAS at residues 12, 13 and 61 is known to result in constitutive activation of downstream effector pathways and deregulation of cell growth, survival and differentiation. These are characteristics of a cancerous state (29). Since KRAS in Caco-2 cells is wild-type, a critical point for consideration is whether inhibition of mutated KRAS by coffee consumption is protective against colorectal cancer. Preliminary data indicated that the growth of HCT116 cells, which have a mutated KRAS at codon 13, is also suppressed by coffee extract, although the inhibition was relatively weak (unpublished data).

Epidemiological studies have indicated that coffee also confers protective effects against other cancers, including liver cancers $(5,28,30)$. KRAS is frequently mutated in 
A

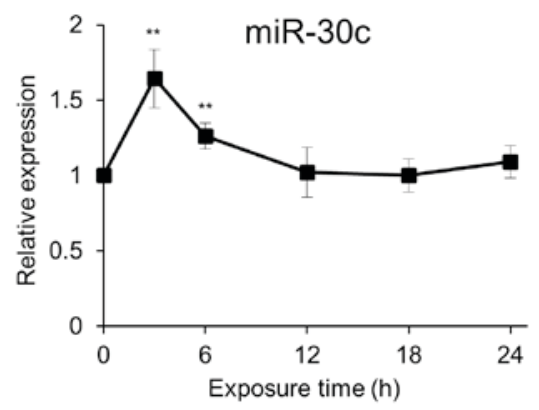

C

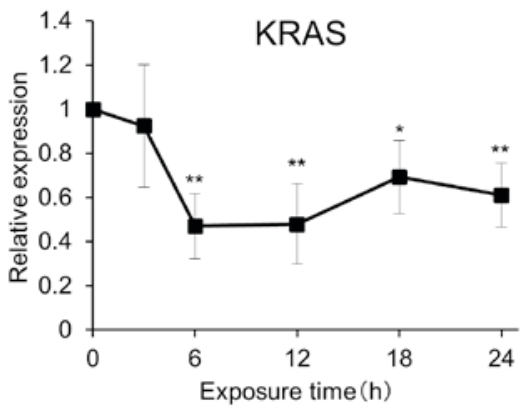

B

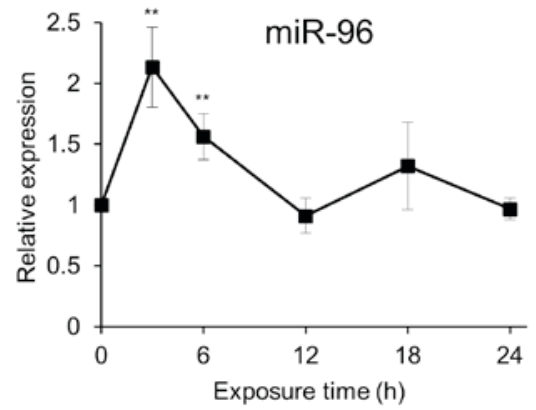

D

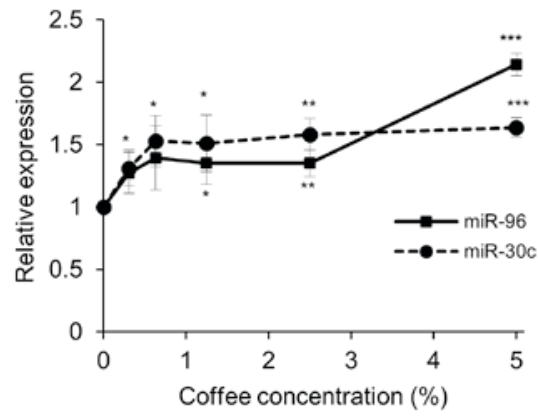

Figure 5. Coffee induced expression of the miR-30c and miR-96 genes in Caco-2 cells. Caco-2 cells were treated with 5\% coffee for the indicated times and the expression of (A) miR-30c, (B) miR-96 and (C) KRAS mRNA were analyzed by qPCR. (D) Cells were treated with 0-5\% coffee extracts for $3 \mathrm{~h}$, and the expression levels of miR-30c and miR-96 were measured by qPCR. ${ }^{*} \mathrm{P}<0.05,{ }^{* *} \mathrm{P}<0.01$ and ${ }^{* * *} \mathrm{P}<0.001$ vs. 0 h (n=3). miR, microRNA; KRAS, KRAS proto-oncogene, GTPase; qPCR, quantitative polymerase chain reaction.

multiple cancers and is therefore an attractive target for cancer therapy (31). Based on the results of the present, coffee constituents that inhibit KRAS expression may be promising candidates for cancer therapy, not only for colorectal cancer but also for other cancers. Further investigations in other cell lines and animals are necessary to identify these active constituents.

\section{Acknowledgements}

The authors would like to thank Dr Kitaro Oka (Emeritus professor of Tokyo University of Pharmacy and Life Sciences, Tokyo, Japan), for his encouragement. The present study was supported in part by a Grant-in-Aid from the Ministry of Education, Culture, Sports, Science, and Technology (MEXT) of Japan (Grant no., 15K00883) and by a grant from the MEXT-Supported Program for the Strategic Research Foundation at Private Universities. The abstract was presented at the 38th ESPEN Congress, Copenhagen, Denmark, 17-20 September 2016, and published as abstract no. SUN-P083 in Clinical Nutrition 35, (Suppl 1): 2016.

\section{References}

1. van Dam RM and Feskens EJ: Coffee consumption and risk of type 2 diabetes mellitus. Lancet 360: 1477-1478, 2002.

2. Ascherio A, Weisskopf MG, O'Reilly EJ, McCullough ML, Calle EE, Rodriguez C and Thun MJ: Coffee consumption, gender, and Parkinson's disease mortality in the cancer prevention study II cohort: The modifying effects of estrogen. Am J Epidemiol 160: 977-984, 2004.

3. Ruhl CE and Everhart JE: Coffee and tea consumption are associated with a lower incidence of chronic liver disease in the United States. Gastroenterology 129: 1928-1936, 2005.
4. Je Y, Liu W and Giovannucci E: Coffee consumption and risk of colorectal cancer: A systematic review and meta-analysis of prospective cohort studies. Int J Cancer 124: 1662-1668, 2009.

5. Yu X, Bao Z, Zou J and Dong J: Coffee consumption and risk of cancers: A meta-analysis of cohort studies. BMC Cancer 11: 96, 2011.

6. Tian C, Wang W, Hong Z and Zhang X: Coffee consumption and risk of colorectal cancer: A dose-response analysis of observational studies. Cancer Causes Control 24: 1265-1268, 2013.

7. Kang NJ, Lee KW, Kim BH, Bode AM, Lee HJ, Heo YS, Boardman L, Limburg P, Lee HJ and Dong Z: Coffee phenolic phytochemicals suppress colon cancer metastasis by targeting MEK and TOPK. Carcinogenesis 32: 921-928, 2011.

8. Lev Z, Kislitsin D, Rennert G and Lerner A: Utilization of K-ras mutations identified in stool DNA for the early detection of colorectal cancer. J Cell Biochem Suppl 34: 35-39, 2000.

9. Campbell SL, Khosravi-Far R, Rossman KL, Clark GJ and Der CJ: Increasing complexity of Ras signaling. Oncogene 17 (11 Reviews): 1395-1413, 1998.

10. Hackel PO, Zwick E, Prenzel N and Ullrich A: Epidermal growth factor receptors: Critical mediators of multiple receptor pathways. Curr Opin Cell Biol 11: 184-189, 1999.

11. Livak KJ and Schmittgen TD: Analysis of relative gene expression data using real-time quantitative PCR and the 2(-Delta Delta C(T)) method. Methods 25: 402-408, 2001.

12. Feinberg AP, Vogelstein B, Droller MJ, Baylin SB and Nelkin BD: Mutation affecting the 12th amino acid of the c-Ha-ras oncogene product occurs infrequently in human cancer. Science 220: 1175-1177, 1983.

13. Oka K: Pharmacological bases of coffee nutrients for diabetes prevention. Yakugaku Zasshi 127: 1825-1836, 2007 (In Japanese).

14. Saud SM, Li W, Morris NL, Matter MS, Colburn NH, Kim YS and Young MR: Resveratrol prevents tumorigenesis in mouse model of Kras activated sporadic colorectal cancer by suppressing oncogenic Kras expression. Carcinogenesis 35: 2778-2786, 2014

15. Luu C, Heinrich EL, Duldulao M, Arrington AK, Fakih M, Garcia-Aguilar J and Kim J: TP53 and let-7a micro-RNA regulate K-Ras activity in HCT116 colorectal cancer cells. PLoS One 8: e70604, 2013.

16. Wang YY, Ren T, Cai YY and He XY: MicroRNA let-7a inhibits the proliferation and invasion of nonsmall cell lung cancer cell line $95 \mathrm{D}$ by regulating K-Ras and HMGA2 gene expression. Cancer Biother Radiopharm 28: 131-137, 2013. 
17. Tanic M, Yanowsky K, Rodriguez-Antona C, Andrés R, Márquez-Rodas I, Osorio A, Benitez J and Martinez-Delgado B: Deregulated miRNAs in hereditary breast cancer revealed a role for miR-30c in regulating KRAS oncogene. PLoS One 7: e38847, 2012.

18. del Castillo MD, Ames JM and Gordon MH: Effect of roasting on the antioxidant activity of coffee brews. J Agric Food Chem 50: 3698-3703, 2002.

19. Paur I, Balstad TR, Kolberg M, Pedersen MK, Austenaa LM, Jacobs DR Jr and Blomhoff R: Extract of oregano, coffee, thyme, clove, and walnuts inhibits NF-kappaB in monocytes and in transgenic reporter mice. Cancer Prev Res (Phila) 3: 653-663, 2010.

20. Paur I, Balstad TR and Blomhoff R: Degree of roasting is the main determinant of the effects of coffee on NF-kappaB and EpRE. Free Radic Biol Med 48: 1218-1227, 2010.

21. Nicoli MC, Anese M, Parpinel MT, Franceschi S and Lerici CR: Loss and/or formation of antioxidants during food processing and storage. Cancer Lett 114: 71-74, 1997.

22. Daglia M, Papetti A, Gregotti C, Bertè F and Gazzani G: In vitro antioxidant and ex vivo protective activities of green and roasted coffee. J Agric Food Chem 48: 1449-1454, 2000.

23. Fogliano V and Morales FJ: Estimation of dietary intake of melanoidins from coffee and bread. Food Funct 2: 117-123, 2011.

24. Nguyen HT, Dalmasso G, Müller S, Carrière J, Seibold F and Darfeuille-Michaud A: Crohn's disease-associated adherent invasive Escherichia coli modulate levels of microRNAs in intestinal epithelial cells to reduce autophagy. Gastroenterology 146 : 508-519, 2014
25. Goparaju CM, Blasberg JD, Volinia S, Palatini J, Ivanov S, Donington JS, Croce C, Carbone M, Yang H and Pass HI: Onconase mediated NFK $\beta$ downregulation in malignant pleural mesothelioma. Oncogene 30: 2767-2777, 2011.

26. Isshiki M, Umezawa $\mathrm{K}$ and Tamura $\mathrm{H}$ : Coffee induces breast cancer resistance protein expression in Caco- 2 cells. Biol Pharm Bull 34: 1624-1627, 2011.

27. Galeone C, Turati F, La Vecchia C and Tavani A: Coffee consumption and risk of colorectal cancer: A meta-analysis of case-control studies. Cancer Causes Control 21: 1949-1959, 2010

28. B $\varnothing \mathrm{hn}$ SK, Blomhoff R and Paur I: Coffee and cancer risk, epidemiological evidence, and molecular mechanisms. Mol Nutr Food Res 58: 915-930, 2014

29. De Roock W, Claes B, Bernasconi D, De Schutter J, Biesmans B, Fountzilas G, Kalogeras KT, Kotoula V, Papamichael D, Laurent-Puig P, et al: Effects of KRAS, BRAF, NRAS, and PIK3CA mutations on the efficacy of cetuximab plus chemotherapy in chemotherapy-refractory metastatic colorectal cancer: A retrospective consortium analysis. Lancet Oncol 11: 753-762, 2010.

30. Bravi F, Bosetti C, Tavani A, Bagnardi V, Gallus S, Negri E, Franceschi S and La Vecchia C: Coffee drinking and hepatocellular carcinoma risk: A meta-analysis. Hepatology 46: 430-435, 2007.

31. Friday BB and Adjei AA: K-ras as a target for cancer therapy. Biochim Biophys Acta 1756: 127-144, 2005. 